\title{
Resource Acquisition In Providing Free Education For Street Children
}

\author{
Titim Eliawati \\ Political Science and Education Faculty \\ Potensi Utama University \\ Medan, Indonesia \\ titim.eliawati@gmail.com
}

\begin{abstract}
There is a need for a flexible education management system yet stable, providing special education services also offering space for street children to adjust the changes of street life to the sedentary life, have a new family and school. School Master has many achievements concerning the interests of street children in acquiring education as high. The purpose of this study was to understand the resources in the acquisition made by School Master in providing free education for street children. This is a qualitative research with case study method, which was held at School Master, Depok City, West Java. The study found that: first, school leader has an experience that is almost the same as street children, which led a very strong internal motivation and encouraged the leader to help street children; second, in order to identify the resources of the requirement at the School Master both short-term and longterm needs emphasized the need to be able to survive either individually of learners and volunteers as well as institutionally in implementing free education for street children; third, friendship is a symbiotic mutualism that is built by sincerity as the main strategy of School Master in obtaining resources. Network development initiated by interpersonal relationships which later grew into the form of collaboration between the school community and its volunteers; fourth, school's leader dominates the resource acquisition planning phase to gain financial resources, real resources, and human resources (volunteers); fifth, Most of real resources and financial acquisition come from outside the school. Otherwise, most of School Master's volunteers would be recruited internally (alumni).
\end{abstract}

Keywords: resources acquisition, free education, street children, and volunteers

\section{INTRODUCTION}

Street child or youth is any girl or boy who has not reached adulthood, for whom the street (in the broadest sense of the word, including unoccupied dwellings, wasteland, etc.) has become her or his habitual abode and/ or sources of livelihood, and who is inadequately protected, supervised or directed by responsible adults (UNICEF, 2010). The street culture which full of freedom, hard and unprotected firmly entrenched in the minds of street children. The low willingness of street children to come and follow the learning process is a challenge for schools. There is a need for education management system to be flexible yet stable in providing special education services and also providing space to street children to adapt the changes from street life into the settle life, having a new family and friends at school. Working with a street child demands involvement over the very long term and a patient approach. The provision of care encompasses a blend of group and individual support, but also an element of emergency intervention on the streets, daytime drop in centresor shelters and a process of reintegration (Agence Francaise de Development \& Samusocial International, 2010).

It is important to conceptually disentange the availability of family and school resources across inner city, rural and suburban places from the educational investment of those resources. People who live in communities with historically limited access to education or modest economic returns to educational investments may simply invest less in education (Roscigno, Tomaskovic-Devey \& Crowley, 2007). On the other hand, Non Formal Education Management is experiencing problems of resources availability, especially funds, real and human resources. Furthermore, public sectors and voluntary organizations also acquire real resources directly, for example in the form of donations of time from volunteers or books and classes equipment. Financial resources come in the form of grants (mainly via the government), voluntary donations, and fundraising or, in a more minor way, from the sale of non-educational services, such as renting premises (Levacic, 2000). Also, emphasized that financial resources for nonprofit organizations typically come from government appropriations, grants, and donations rather than from the sale of products or services to customers (Daft, 2012). School managers have the freedom or the opportunity to acquire 'additional' resources depends on the nature of the school or college (Anderson, 2002). The school leader has to create resources master plan in order to fulfill the requirement of resources. The key to implement any plan is to first identify the parameters, needs, and options available. Then, the second step is to identify the strategies that are available for achieving the outcomes (Schilling \& Tomal 2013).

Depok City is a metropolis which is directly adjacent to Jakarta. Therefore, Depok city became one of the buffer areas of Jakarta. In 2011, the population of Depok city reached more than 1.7 million people. According to the data from Social Empowerment Direct Aid, the number of impoverished people who live in Depok on 2011 is 53.252 The number of street children in the city of Depok reached 700 children in the same year. In this city also has established School Master which is a public school that provides free education for street children. The school was 
educating 1608 children in 2015 that include street children and children from poor families. Based on the quantity of school activities in providing free education and facilities for street children, school achievement, the number of street children who nurtured by the school, the author decided to set School Master as the background of this research. In this paper, the author presented the main results of the acquisition of resources in providing education of street children. The result includes identification of resource requirements, resource acquisition strategy, and the process of acquiring resources.

\section{RESEARCH METHOLOGY}

The research was conducted in School Master (Masjid Terminal), Depok City, West Java, Indonesia. Referring to the focus of the study, the approach used in this study was a qualitative approach with case study method. Researcher observed the interaction within people in the school. The researcher also interacted with the subject of research and tried to understand and interpreted the language and their interpretation of the acquisition of resources.

The method used in this study was a single case study with the intention of obtaining a higher meaning of resources acquisition in School Master. The research activity was an iterative process (cycle) with three main stages, namely: 1) exploration of a widespread and thorough and usually still moving on the surface level, 2) Focus and selective exploration in order to achieve a certain level of depth and detail, and 3) confirming the research findings. This study was not only exploratory nature but also are explanatory, which was seeking and analyzing the resource acquisition that occurred, seeking information or aspects and causation arguments in order to know the uniqueness, singular distinctiveness and answers. In this study, researchers act as the main instrument.

The data in this study were divided into two categories, primary data and secondary data. Determination of sample in this research was purposeful sampling by reasons: first, the subject has been quite a blend in the school activities environment; second, the subject is still engaged fully and actively in the targeted research; third, the subject has ample times and opportunities to be interviewed. The researcher determined the key informant among all informants. The key informant in this research is the founder and leader of School Master.

The data collection technique which conducted by researcher in the background or any natural setting as follows:

\section{A. Observation}

Observation was done by engaging with people in a situation that was being studied. In the process, the observation was made in two stages, initial observation and continuation observation. It was observed physical objects (geographic and demographic), the personnel involved in the management of resources, the actions and attitude of the personnel in carrying out the tasks related to the management of resources, the events that occurred, and time of implementation. The next stage was focused and selective in seeking social situation in education of street children in more detailed and depth according to the selected domain. The observations are documented in field notes. The note was used to define the next research activity plan.

\section{B. Interview}

The form of interviews conducted was structured interview and unstructured interview. The interview process began with the creation of rapport that was to build a supportive atmosphere, mutual trust and openness based on the principles of honesty, partnership and alignment.

Determination of informants used snowball sampling, so the founder of School Master designated as the key informant in the preliminary interview. Thus informants consisted of key informant which was the founder and leader of the school; escort informants were the chairman of the board, head of education division, head of fostering division, head of partnership division, head of research and development division; and triangulation informants were coordinator package A, package B coordinator, the coordinator of the package $\mathrm{C}$, life skills program coordinator, coordinator public reading; tutors and students.

\section{Documentation Study}

The documentation helped the researcher to deepen information obtained from observations and interviews. The documents were in the form of written and audio visual or photo-voice which relate to this research.

Data analysis was performed when researcher was in the field. Data analysis is a process of structuring in systematic way to record interviews, observation and documentation. In analyzing the data that has obtained, researcher used Miles and Huberman model. In this research, the data analysis used words which were organized into expanded texts.

In order to get the valid and reliable data, it would require an examination of the validity of the data in this study either obtained through observation, interviews and documentation. The validity examination of the data in this study was credibility involved source triangulation, techniques triangulation, and triangulation of time. The other examinations were transferability and dependability.

\section{RESEARCH RESULT AND DISCUSSIONS}

\section{A. Similarity of Youth Life Experiences Led a Very Strong Internal Motivation and Encouragement to Provide Education for Street Children}

Life experiences of a person can affect his ability to make decisions on issues that arise. School's leader who has the same life background with street children will always have a strong motivation from within him to provide the best services to street children. Drive related to their high conscientiousness and positive self-concept, successful leaders have a high need for achievement. This drive represents the inner motivation that leaders possess to pursue their goals and encourage others to move forward with theirs. 
Drive inspires inquisitiveness, an action orientation and boldness to take the organization or team into uncharted waters (McShane, 2013). Experiences that possessed by a leader became a specific knowledge for him to understand the needs of street children and how these resources are acquired and managed for the success of the organization in providing the best education for street children. You will always have something more to learn, so be prepared to profit by experience. Experience helps a great deal. Take every opportunity of gaining experience in leadership (Adair, 2010). The above findings indicated an association with the strategies which used by school leader to focus more on recruiting human resources from schools internally. Life experiences of alumni of the school and school attachment with street children became a tight rope which keeps guarding the commitment of volunteers to work at School Master. It also helps street children to adjust with the school environment. Street children feel comfortable with someone who understands them. It is easy for them to be admired by adult people who have the same life experiences with them and success to leave the street life. Children who have already been in trouble or those who have family members who took the wrong path are often inspired by seeing those who have emerged on the other side after some bad decisions. School Master set an example for those children, a way of showing how lives can be turned around.

\section{B. The need to survive becomes the focus of School Masters in the process of identifying its needs}

Needs identification for both short-term and long-term needs emphasized the fulfillment of School Master needs to be able to survive either individually and institutionally. The cycle of School Master identifies it needs can be seen comprehensively in Figure 1.

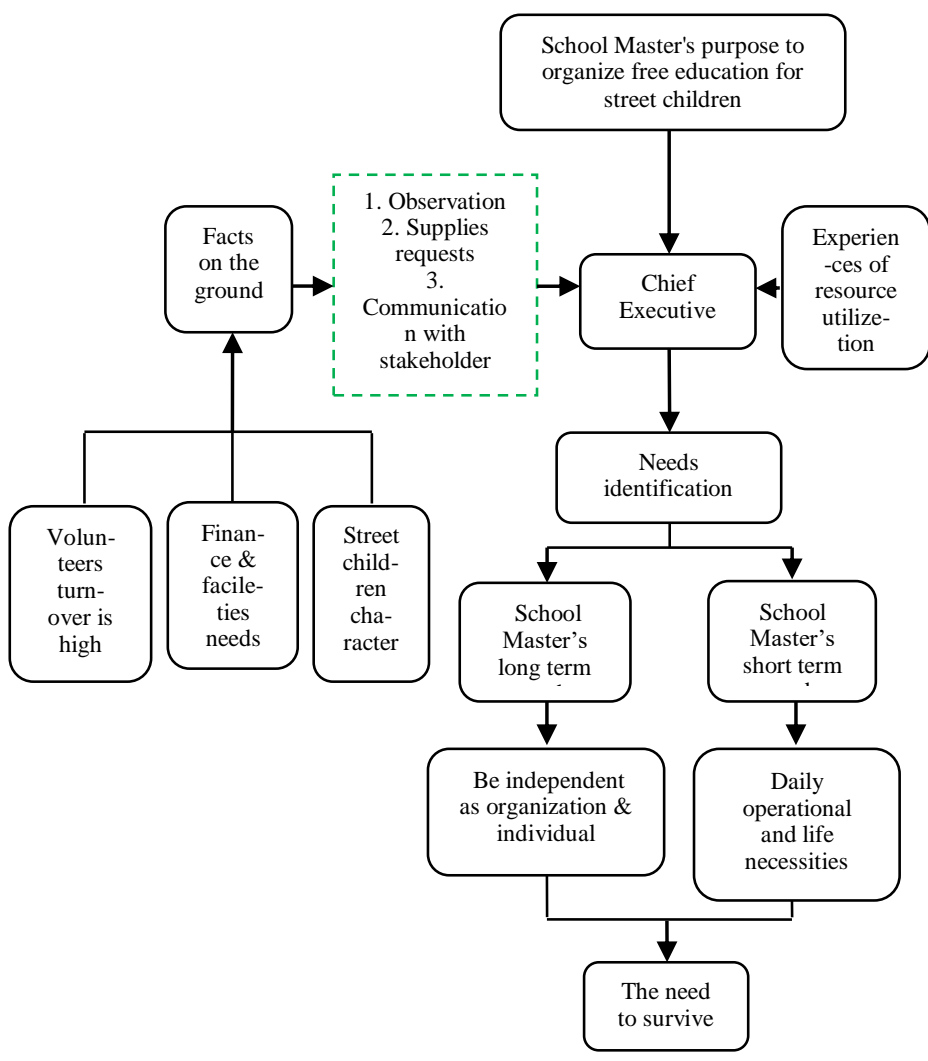

Figure 1. Identification School Master Needs
Short-term needs is the school operational needs that related to school daily activities, which was both directly and indirectly related to teaching and learning activities in the classroom. Short-term and long-term facilities planning is an important pieces of a district's overall financial plan. Review of demographics, instructional strategies, safety and security issues, building inventories and capacities are all important in determining future facility needs. Having staff and professional staff provide annual feedback on the condition of buildings and facilities will lead to better planning (Schiling \& Tomal, 2013).

School Master as foundation that provides services to street children saw the need and looked for a solution for street children to get their rights, especially the right to education. Therefore, the need of the school was a reflection of its students needs both at present and in the future. The identification of the availability of parameters, needs and choices to the school help the school's leader to develop a plan for attracting the specific needs into the school. The challenge in reforming schools, therefore, is first to identify which resources are effective and then to allocate funding, other resources, and energy and resources to increase these effective resources rather than simply allocating more money across the board (W.N. Grubb, 2008).

The identification of resource needs is done by drafting a map of the school's needs based on the objectives, needs and experiences of the previous period. Schools will have a capacity for 'backward mapping' in the design and implementation of programs for learning, starting from goals, objectives, needs and desired outcomes, and working backwards to determine courses of action that will achieve success, utilizing where possible and appropriate the capacity that accrue with self-management (Caldwell, 2000).

In identifying the needs of volunteers, school's leader customized it with the concept of school-based volunteers, the character of the street children and other vulnerable children, the number of learners that are not comparable with the availability of educators. School-based volunteers are always facing problems of shortage of human resources for the loyalty and the capabilities they provide to school are not comparable with the award which given by school. Human resources administrators needed to examine carefully all the factors that motivate employees for good performance other than only relying upon the payment and benefits. There are many different types of compensation programs, which include pay for the performance, skills based, knowledge based, gain sharing, and merit plans, that can be successfully utilized by the school board (Schilling \& Tomal, 2013). Therefore, the leader of School Master identified that the problem of the need on high quality volunteers is one of the significant challenges to the school.

\section{Friendship on the Basis of Sincerity is the Main Strategy of School Master in Obtaining Resources}

The resource management framework can be used to identify, develop, and coordinate strategies to improve the capacity of institutions to achieve their goals and objectives (John, 1991). The strategy used by School Master leader in attracting the resources for schools is friendship which is one 
of the school strengths. Friendship is built on personal relationship which later grew into the form of partnership between schools and the funding institutions. The leaders grew mutual partnership (symbiotic mutualism).

The ability of school leader in establishing a relationship with communication and helping each other has growth some trusts from community to the school leader. Friendship braided by school leader with the media, individual and institutional communities. Mutual cooperation are described the value of a partnership is that, over time, trust and understanding of each partner's strategies and culture can be achieve which, in turn, makes it more likely that ways can be found for them to work together to mutual benefit or, indeed, for the company to support the school or college through donations (Anderson, 2002). The value of partnership such as trust and understanding of the strategy and culture of each party is built over time. Therefore the partnership would find the best way to build beneficial partnership. This study produced a map of School Master's strategy to attract resources that can be seen at Figure 2.

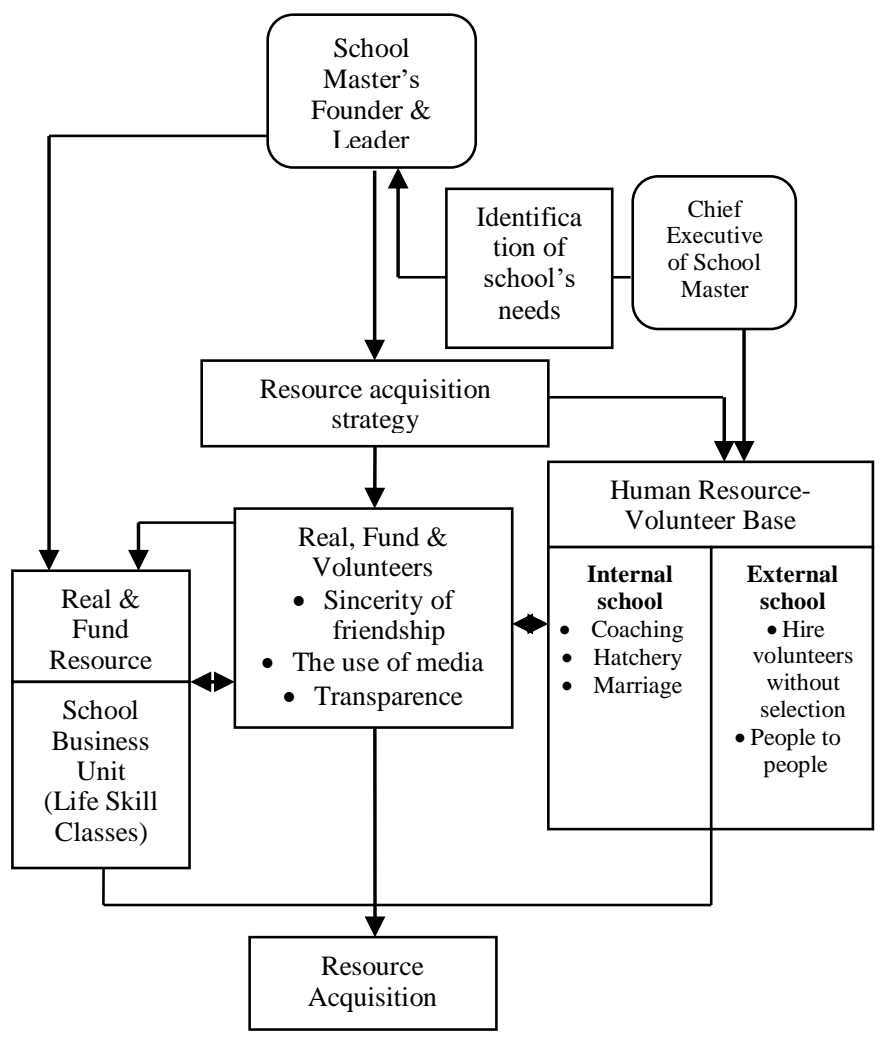

Figure 2. The Strategies of Acquisition of Real and Financial Resources

The school leader builds friendship in personal relationships first and then grows it into forms of cooperation between the school and the community of individuals and institutions. At the task environment level, there has to be a relationship with the local community to top up the resources and to offer actual and moral support (Glover \& Levacic, 2007). In the environmental sphere, there must be a relationship of the school with the local community to get the resources and support.
School Master has an open system as an organization. School accepts anyone who wants to get to know them. They also accept whatever is given unless something that can be detrimental the school. The relationship of the organization with its external environment is crucial in relation to resources. The more open an organization is to its external environment and the more dependent it is on securing support from its stakeholders, the more its survival and success depend on sustaining a flow of resources into the organization and providing stakeholders with the services they demand (Levacic, 2000).

The friendship strategy also applied in an attempt to get volunteers that is by recruiting volunteers from external and internal school. Externally, School Master prefers to be passive and wait anyone from outside the school to join them as volunteer. While the movement of the volunteers to invite their family and friends are allowed by the school. Volunteer's movement is enough to help the school to get some new volunteers. On the other hand, School Master more focuses on internal recruitment in order to get volunteers with high commitment. Recruitment is done through the internal regeneration which translates into three activities, namely nurturing, hatchery and marriage.

Coaching volunteers include several activities, namely: offer an opportunity to each volunteer to take part in various training both related to classroom learning or life skills, providing help to the volunteers in the form of a loan for tuition fees and the necessities of life and the search for scholarships, as well as giving attention their high school alumni achievers. Hatchery meant School Master would support any similar schools or organizations that have a common goal which is providing an education for street children and children in poverty. It offers help in any way to get those schools survive and could operate for a long time. Volunteers who have the same vision and mission with the School Master and still not married would be supported to get married so that it appears a strong bond between School Master and its volunteers. The school will help them financially to gain volunteer's education. Helping employees continue their educations often strengthens their current performance and their future job prospects. Increasingly, employees see training opportunities as ways to augment their skills, increase their responsibilities on the job, and to enhance their marketability for jobs in the future (Masaoka, 2011).

There was a disadvantage of School Master leader's decision to recruit more volunteers internally that it needs long time to train school graduates became teachers and administrative staff at the school. In addition, it gives concern that the volunteers cannot give new ideas to the school because they do not see the school conditions from outside perspective. A disadvantage to internal hiring is that you lose the opportunity to bring in fresh blood and a different perspective from the outside. Every organization suffers to some degree from groupthink, and particularly at the senior level, there are distinct advantages to bringing in fresh eyes and different kinds of backgrounds (Masaoka, 2011). 
The school's leader knew that school needs volunteers who are able to understand the character of the street children. Therefore, it is understandable the school's reason that prefers volunteers who had been recruited internally compared to volunteers from outside the school. The leader school believed that the external volunteers tend to leave the school quickly. It interfere the school stability as a whole. Volunteers who come from alumni considered understanding the character of the street children and other vulnerable children, and they have a strong commitment to the school. They believe that they need to pass on their knowledge to the younger learner. It is their pay back to the school as the school provided them free education. Thus street children would be expected to follow the learning process in the classroom. The difference in the probability of giving between volunteers and non-volunteers provides an important value added dimension for nonprofit managers to consider when evaluating the potential contributions volunteers also make to the financial solvency of the charities in the subsectors with which they feel strong alignment (Van Slyke \& Johnson, 2006).

\section{School Master's Leader Dominate the Resource Acquisition Overall}

The leader as the planner and he becomes the actor in developing the relationship between the school and the community. School Master is dominated by two leaders in which the founder as strategic leader and chief of executive as operational leader. Operational leader is the leader of one of the main parts of the organization and more than one's control. Strategic leader is the leader of a whole organization, with a number of operational leaders under one's personal direction (Adair, 2010). The role of the founder as the only one to establish a relationship with the outside of school is very important. He became the planners and performer in the development of relationship between the school and the community. His ability in open communication with the community raises their confidence to believe in him. The organization lives, survives and adapts via its interlink ages with the external environment. From an open systems perspective an effective organization is one which adapts well to changes in its external environment and continues to serve the latter's needs (Levacic, 2000). The founder is a good figure for all volunteers in School Master.

School-based volunteer has a high dependence on the leader. School needs a leader who has the skills in managing school operational activities and covering the weaknesses of the deficiencies in the identification of needs which was done as a team. On the other hand the chief executive can also play an important role internally. $\mathrm{He}$ is responsible in taking decision for technical issues.

The founder needs someone who could translate his thoughts into tangible form and technical activities. His imagination was translated by the chief executive into the vision and mission of the School Master. Strategic leaders need imagination to see new possibilities in the present or the future. Imagination refers to the mind's power to call up images, to picture or conceive things that are not actually before the eye or within the experience (Adair, 2010). The founder collaborates with the chief executive in doing most of the acquisition of financial resources, infrastructure and volunteers. As resource managers, bursars have a strong involvement in HRM at administration, management and leadership levels, and HRM is included in all the job descriptions surveyed and identified as the second largest responsibility area (Wood, 2000). Both leaders share the task of identifying the needs of the school, planning and implementing resource acquisition strategy till the resources received by schools.

\section{E. The process of attracting the resources in the school}

Scarcity of real and fund resources that the school had cause the school to be open to the public outside of school. The process of acquisition of real and fund resources from outside the school is inseparable from the status of the resources. The status can be binding or nonbinding. The status can determine the freedom of the leader to take decisions independently or not in allocating resources that they earn. The resources that are binding cause school leaders to compromise on the contributor. In addition, the ability of schools to be transparent and utilize the resources efficiently and effectively determines the sustainability of the partnership of the school with the contributor. Accountability requires that state-funded schools should demonstrate that they are able to use resources efficiently and effectively, a recurring theme (Glover \& Levacic, 2007).

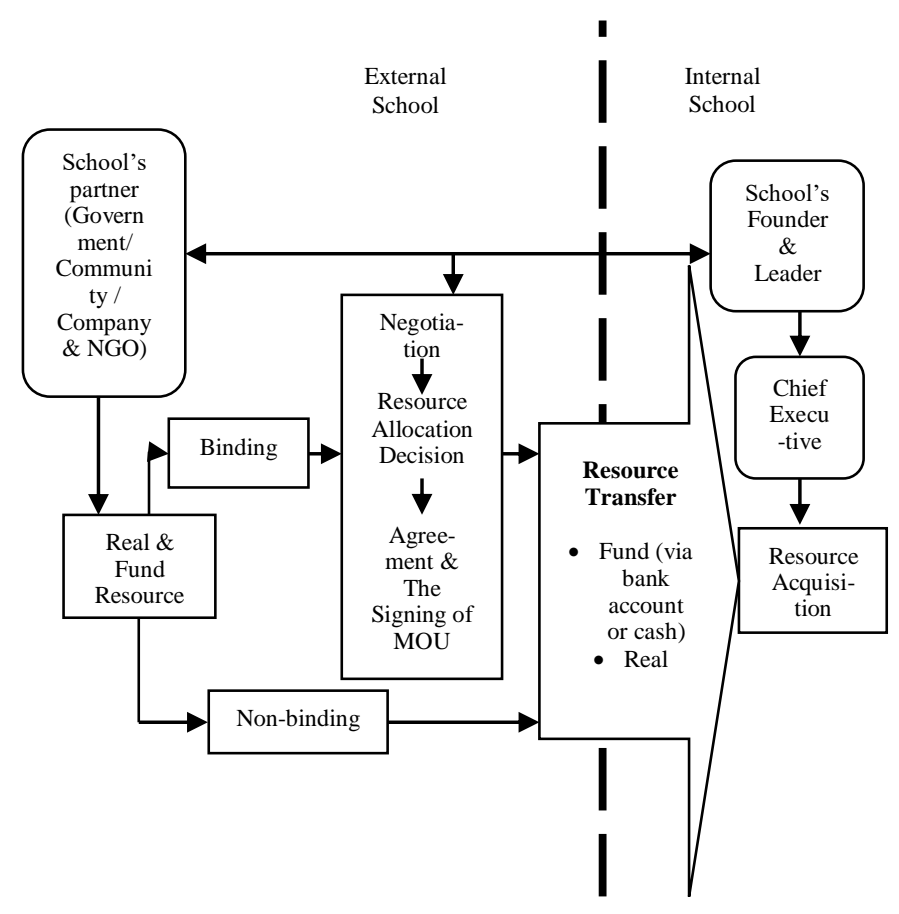

Figure 3. Acquisition Process of Real and Finance Resources 


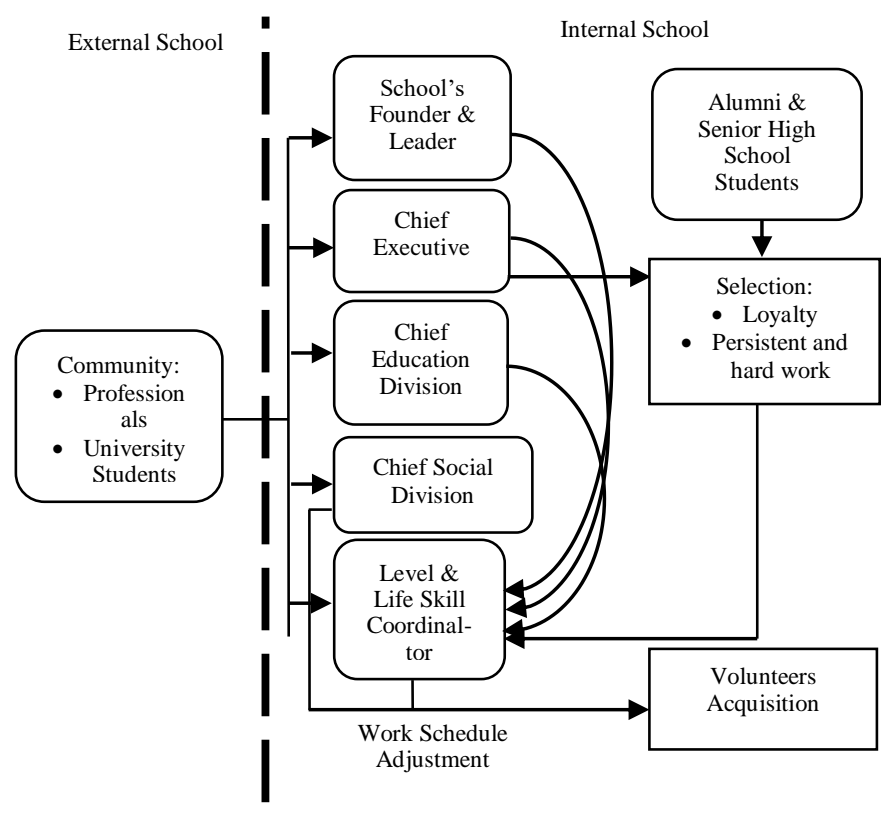

Figure 4. Volunteers Recruitment Process

The above is in contrast to the recruitment of volunteers which more focused on recruitment internally. This showed the desire to achieve the independence in providing human resources for the school. The school wants volunteers who have understood the complexity of the problems that exist in the schools and school culture in order to provide services to street children. Whether you have a full-fledged HR department or a lone, "sole provider" HR person, HR should work with managers to ensure that a strong candidate is found, hired properly, and effectively brought into your organization (Masaoka, 2011). Chief executive has a close kinship with the volunteers. He lives in the school which also builds a sense of community with the volunteers and the children. Such interactions are utilized by the chief executive to know better the street children.

\section{CONCLUSION}

A strong commitment that is owned by the founder of School Master provides a positive impact on transparency in obtaining resources. His commitment and loyalty are high because of the similarity experience of life with the street children.

In order to identify the resources of the requirement at the School Master both short-term and long-term needs emphasized the need to be able to survive either individually of learners and volunteers as well as institutionally in implementing free education for street children. Human resource needs are the substantial challenge for the school. Therefore, the concept of regeneration implanted must be done structurally and professionally and are not dependent on a particular person but began with the construction of regeneration system that involves senior volunteers of School Master.

The dominance of school leader in the process of resources acquisition has positive and negative effects. The negative impact resulting reliance on the leader of the school is very high. Shifting tasks of school leaders to younger volunteers needs to be done in order to establish the links with the community. It is important for the school to gain and keeps the trust from the community (individual and companies).

Friendship is a symbiotic mutualism that is built by sincerity as the main strategy of the School Master in obtaining resources. Network development beginning of interpersonal relationships which later grew into the form of collaboration between the school community and its volunteers Partnerships are built by the school with the community, is conducted equally without any party feels higher than the other. The concept of equality between the donor and recipient must be maintained by the School Master to prevent intervention in decisions relating to the provision of the best services to street children.

In addition, the results of this study can be a guideline for organization of non profit in providing free education to street children and policies for conducting learning system to vulnerable children. Also, the needs to research more in school management (formal and non-formal) for street children are high. The further research in resource management included evaluation the use of the resources for nonprofit organization are important to be conducted. Therefore, the result of this research can be a guideline for the next research to strengthen the school resource management.

\section{ACKNOWLEDGMENT}

The authors thank Mr. Nurrohim and the volunteers of School Master for their help on this research.

\section{REFERENCES}

[1] Agence Francaise de Development \& Samusocial International, Street Children: from individual care to the introduction of social policies. Seminar on street children, p. 42, November 2010.

[2] B. Dyck and M.J. Neubert, Principles of Management. Ohio: SouthWestern, 2009.

[3] C.A. Schilling and D.R. Tomal, Resource Management for School Administrators. Maryland: Rowman \& Littlefield Education, 2013.

[4] D.C. Mosley, L.C. Megginson \& P.H. Pietri, Supervisory Management: The Art of Inspiring, Empowering, and Developing People, 6th Edition. Ohio: South-Western, 2005.

[5] D. Glover, and R. Levacic, Educational Resource Management - An international perspective. London: Institute of Education, University of London, 2007.

[6] D.M. Van Slyke and J.L. Johnson, Nonprofit Organizational Performance and Resource Development Strategies: Exploring the Link between Individual Volunteering and Giving, Public Performance \& Management Review, Vol. 29, No. 4, M.E. Sharpe, Inc., 2006, pp.467-496.

[7] E.P.St. John, A Framework for Reexamining State ResourceManagement Strategies in Higher Education, The Journal of Higher Education, Vol. 62, No. 3. Ohio: Ohio State University Press, 1991, p.271.

[8] F.C. Lunenburg and A.C. Ornstein, Educational Administration: Concepts and Practices, 6th Edition. Kentucky: Wadsworth Cengage Learning, 2012.

[9] J. Adair, Effective Strategic Leadership, London: Macmillan Publishers Limited, 2010. 
[10] J. Dunham, Developing Effective School Management. London: Routledge, 1995.

[11] J. Masaoka, the Nonprofit's Guide to Human Resources. California: Nolo, 2011.

[12] J.W. Creswell, Qualitative Inquiry \& Research Design, 2nd Edition. London: Sage Publications, 2007.

[13] L. Anderson, Resource Acquisition and Allocation, Ed. T. Bush and B. Les, London: Paul Chapman Publishing, 2002.

[14] L. Huckman, Successful Collaborative Resource Management in Small Primary Schools, Management in Education, Vol. 13, British Educational Leadership, Management \& Administration Society, 1999, pp.23-24.

[15] M.B. Miles and A.M. Huberman, Qualitative Data Analysis, a Sourcebook of New Methods. Beverly Hills: Sage Publications, Inc., 1984.

[16] M. Coleman and L. Anderson, Linking Resources to Learning Outcome. London: Paul Chapman Publising, 2000.

[17] M. Weaver, Resources Management. Massachusetts: ButterworthHeinemann, 1998.

[18] McShane. Organizational Behavior. New York: McGraw-Hill, 2013.

[19] R.L. Daft, New Era of Management. 10th Edition, Ohio: South Western, Cengage Learning, 2012.

[20] R.L. Miller, Economics Today, 16th Edition. Boston: Pearson Education, Inc., 2012.

[21] UNICEF, "A Study on Street Children in Zimbabwe," unpublished.

[22] V.J. Roscigno, D. Tomaskovic-Devey and M. Crowley, Education and the Inequalities of Place, Social Forces, Vol. 84, No. 4. Oxford: Oxford University Press, 2007, pp.2121-2145.

[23] W.N. Grubb, Multiple Resources, and Multiple Outcomes: Testing the "Improved" School Finance with NELS88, American Educational Research Journal, Vol. 45, No. 1, American Educational Research Association, 2008, p.111. 